Vibration Testing of Dallas/Maxim iButton Temperature Logger, Model DS1999L, for Flight Qualification on Captive Flight Test Unit-B (CFTU-B)

G. Jacobson, A. Lavietes

June 22, 2005 
This document was prepared as an account of work sponsored by an agency of the United States Government. Neither the United States Government nor the University of California nor any of their employees, makes any warranty, express or implied, or assumes any legal liability or responsibility for the accuracy, completeness, or usefulness of any information, apparatus, product, or process disclosed, or represents that its use would not infringe privately owned rights. Reference herein to any specific commercial product, process, or service by trade name, trademark, manufacturer, or otherwise, does not necessarily constitute or imply its endorsement, recommendation, or favoring by the United States Government or the University of California. The views and opinions of authors expressed herein do not necessarily state or reflect those of the United States Government or the University of California, and shall not be used for advertising or product endorsement purposes.

This work was performed under the auspices of the U.S. Department of Energy by University of California, Lawrence Livermore National Laboratory under Contract W-7405-Eng-48. 


\section{Vibration Testing of Dallas/Maxim iButton Temperature Logger, Model DS1999L, for Flight Qualification on Captive Flight Test Unit-B (CFTU-B) \\ Test Number 001}

Test performed 26 April 2005

Prepared by:

Gerard F. Jacobson 29 April 2005

Engineering Technical Associate Defense Sciences Engineering Division Lawrence Livermore National Laboratory

Approved by:

Anthony D. Lavietes Engineer

Defense Sciences Engineering Division Lawrence Livermore National Laboratory 


\section{Introduction}

This report documents the flight qualification testing of the Dallas/Maxim iButton temperature logger, model DS1922L, for internal mounting to the W80 Air Launched Cruise Missile (ALCM). A single test was performed utilizing a Labworks Inc. LW-140110 electro-dynamic vibration system in Building 131, Room 2272, at Lawrence Livermore National Laboratory, Livermore, California. Two DS1922L temperature loggers were tested simultaneously, one horizontally and one vertically.

The test consisted of random excitation in the vertical axis for 5-hours. The test spectrum used is a shaped random spectrum defined by the Boeing Company for flight qualification of all modifications flown on ALCM flight tests. The spectrum is defined from 10 to $2000 \mathrm{~Hz}$ with a $8.52 \mathrm{~g}$ RMS magnitude. The spectrum is given in Table 1 and shown graphically in Figure 1.1

Table 1

Flight Qualification Test Spectrum

\begin{tabular}{|c|c|c|}
\hline Break Point & $\begin{array}{c}\text { Frequency } \\
(\mathrm{Hz})\end{array}$ & $\begin{array}{c}\text { PSD } \\
\left(\mathrm{g}^{2} / \mathrm{Hz}\right)\end{array}$ \\
\hline 1 & 10 & 0.026 \\
\hline 2 & 50 & 0.026 \\
\hline 3 & 60 & 0.03 \\
\hline 4 & 600 & 0.03 \\
\hline 5 & 800 & 0.03 \\
\hline 6 & 2000 & 0.03 \\
\hline
\end{tabular}

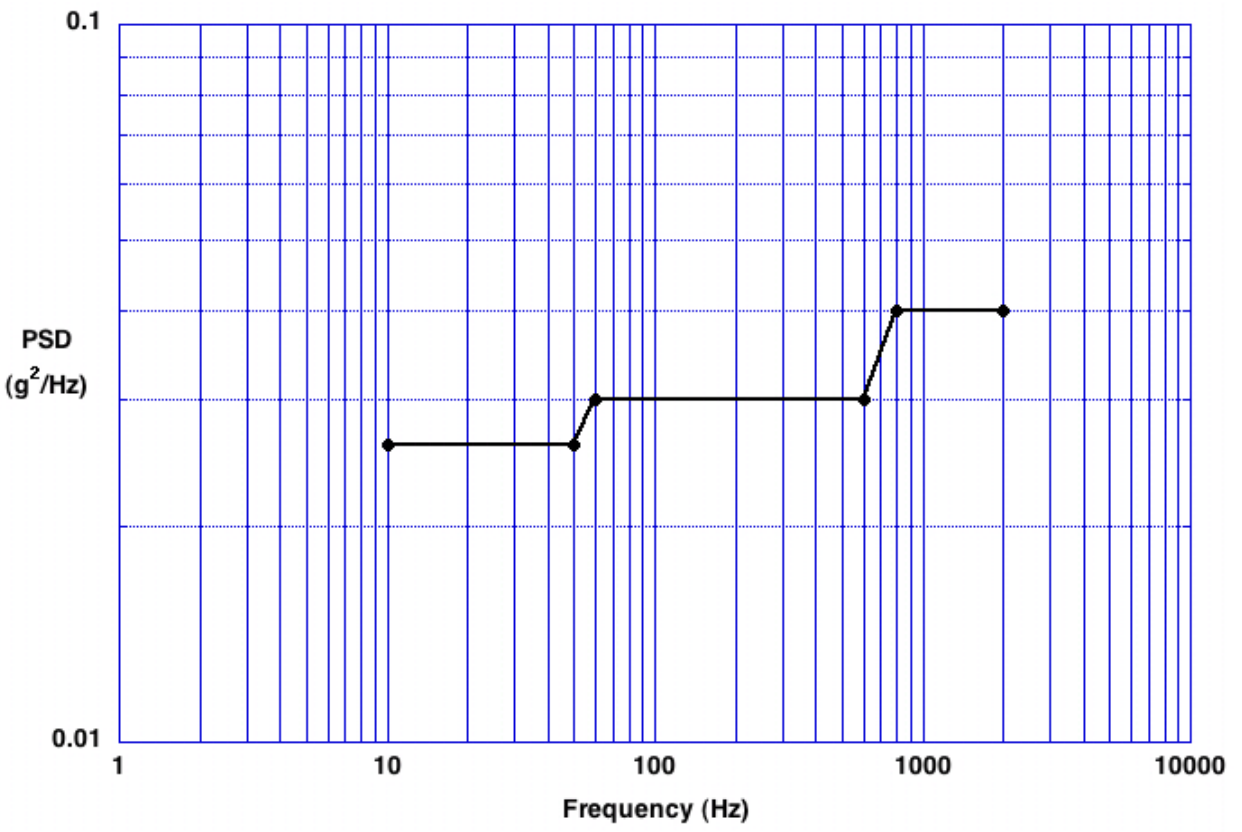

Figure 1.1 ALCM Flight Qualification Test Spectrum 


\section{Test Setup and Procedure}

A Kistler accelerometer, type 8636B50M05, S/N C196770, was attached at the center position of the shaker mounting plate of the shaker head for use as the reference/control accelerometer. An aluminum mounting plate was attached to top of the shaker using four 10-32 x 1" cap head screws, Figure 2.1. The shaker is controlled using VibeLab Pro Digital Sine, Random, and Shock Vibration Controller. It is a pc-based vibration test controller.

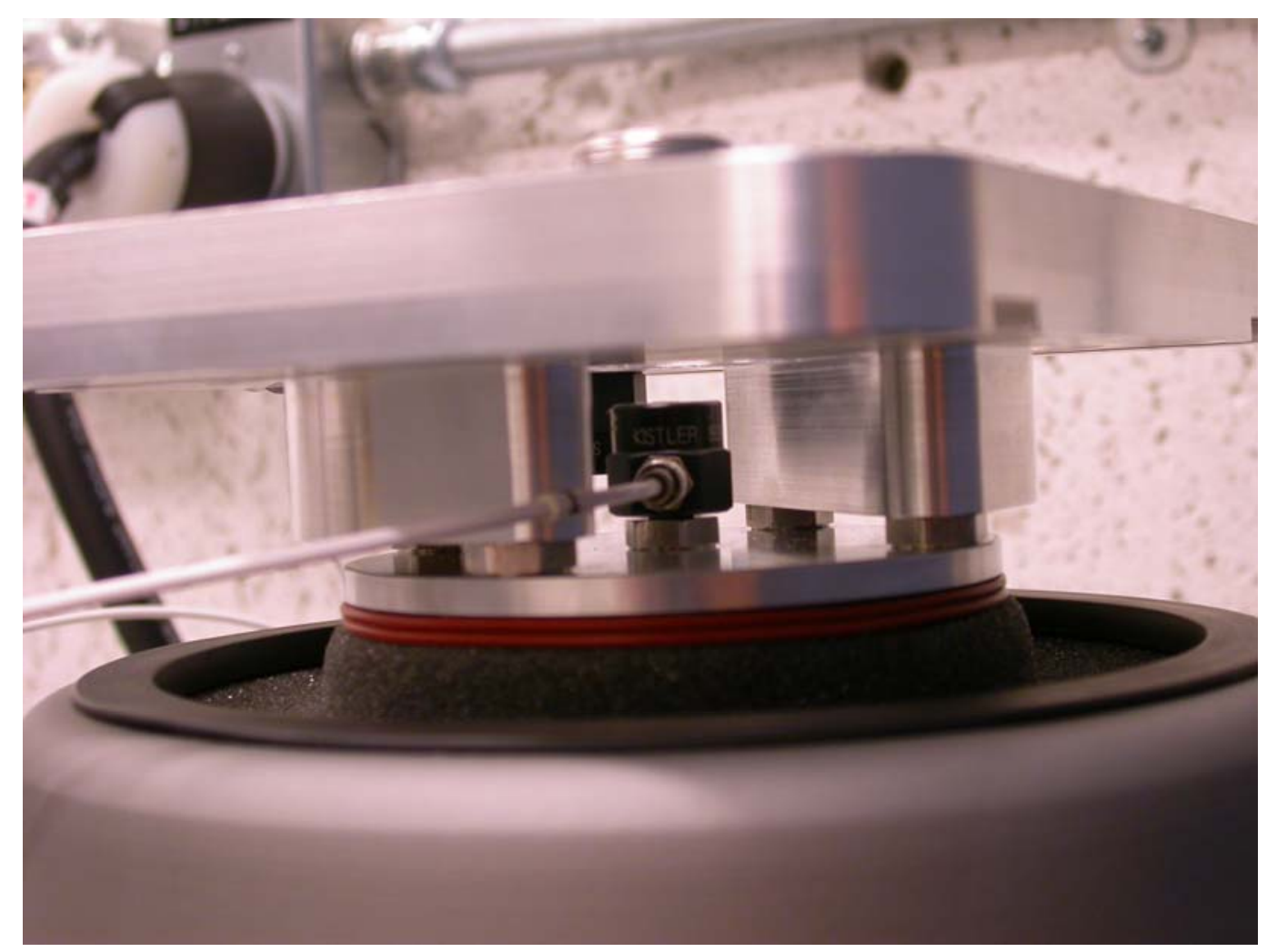

Figure 2.1 - Reference/control accelerometer and mounting plate.

A second Kistler accelerometer, type 8636B50M05, S/N C196961, was attached to the bottom horizontal surface of the mounting plate between the 10 and 11 o'clock positions, Figure 2.2. This accelerometer measured the response of the mounting plate to the test spectrum. 


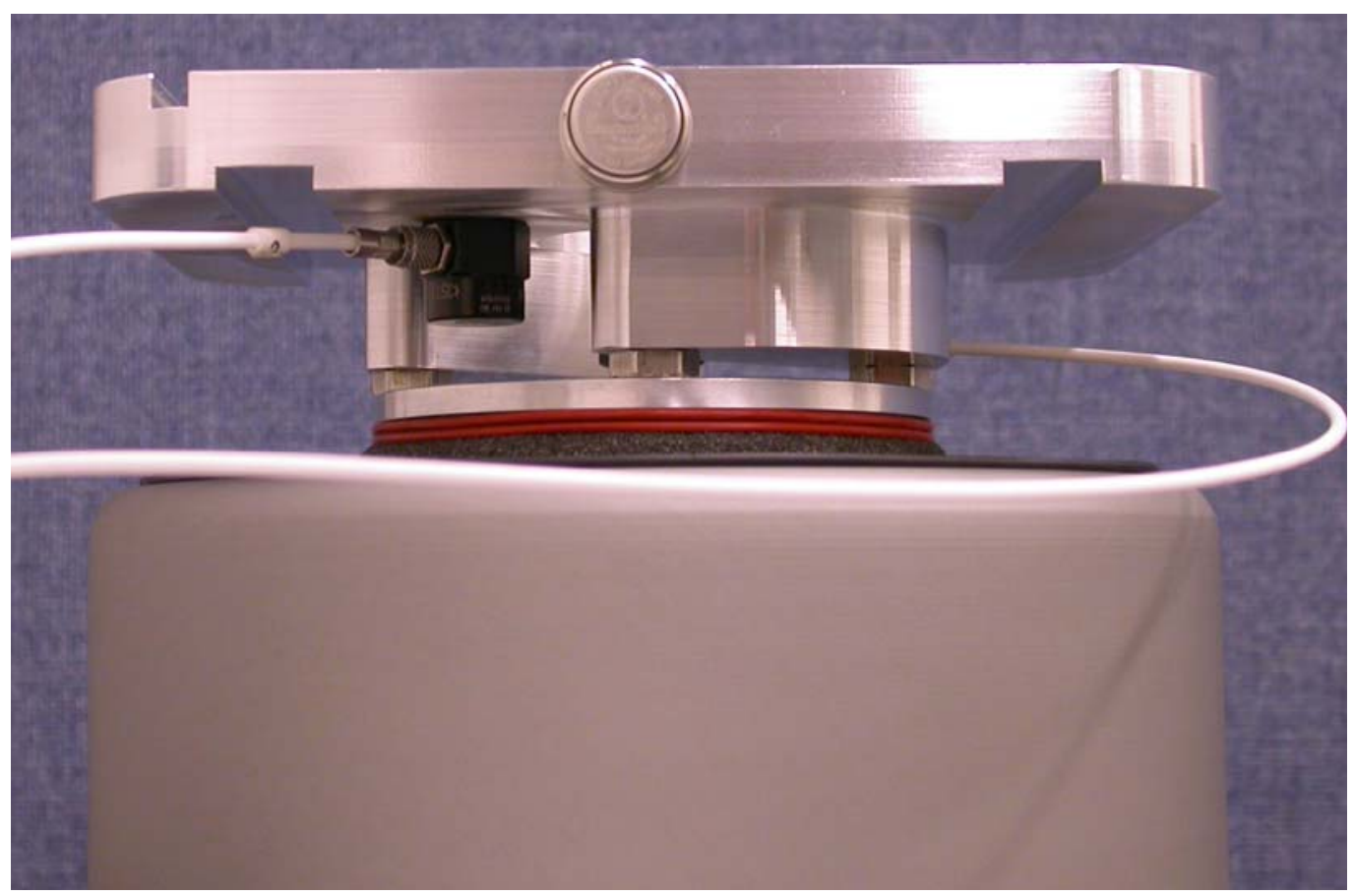

Figure 2.2 - Second accelerometer position.

The top horizontal surface, left side surface of the mounting plate and the bottom the two DS199L temperature loggers were cleaned using IPA. The two DS1922Ls were attached to the plate, one horizontally, S/N 3800000001F63541, and the other vertically, S/N 8F0000000200F41, using adhesive pads, Dallas/Maxim model DS9096P, Figures 2.3-2.4.

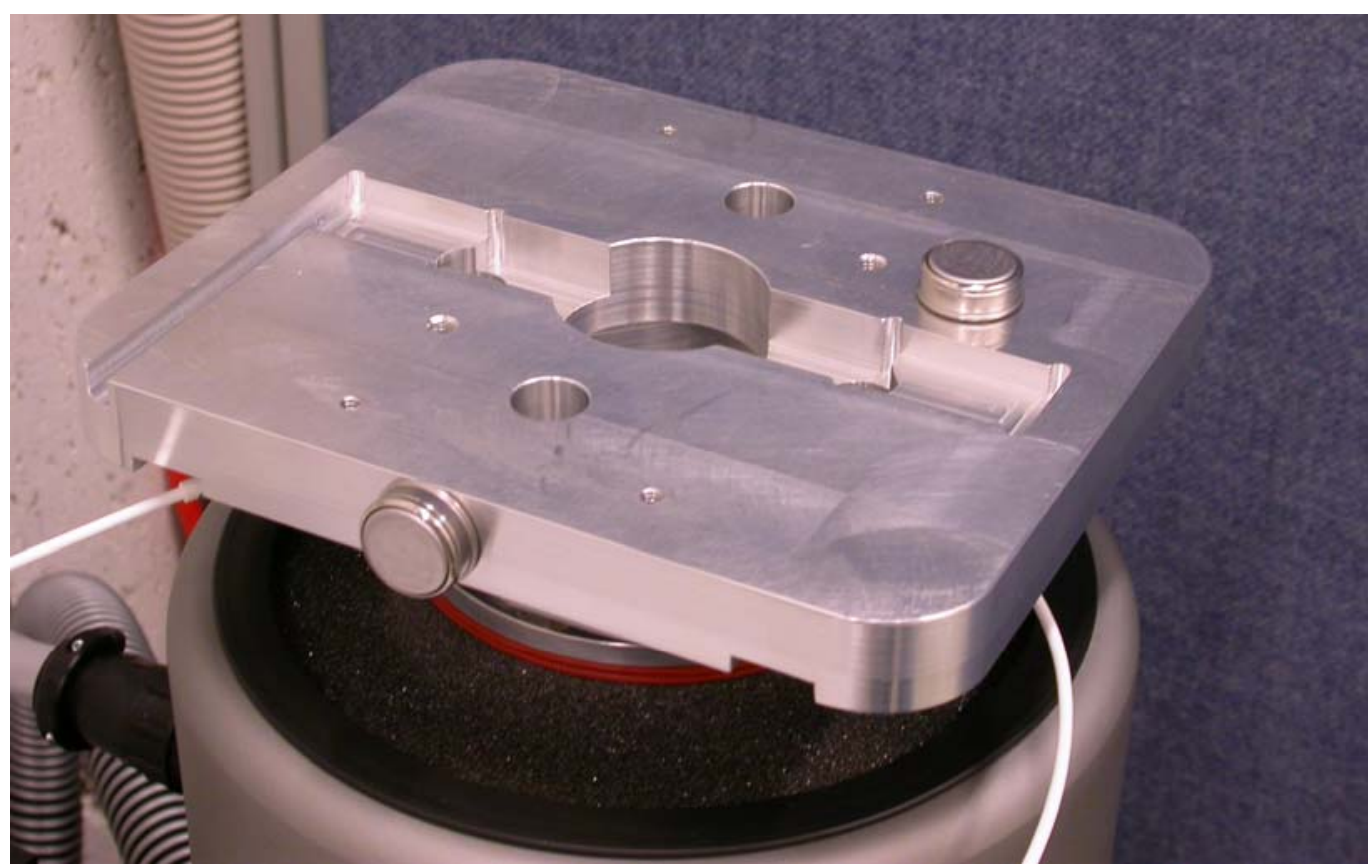

Figure 2.3 - Placement of DS1922L temperature loggers. 


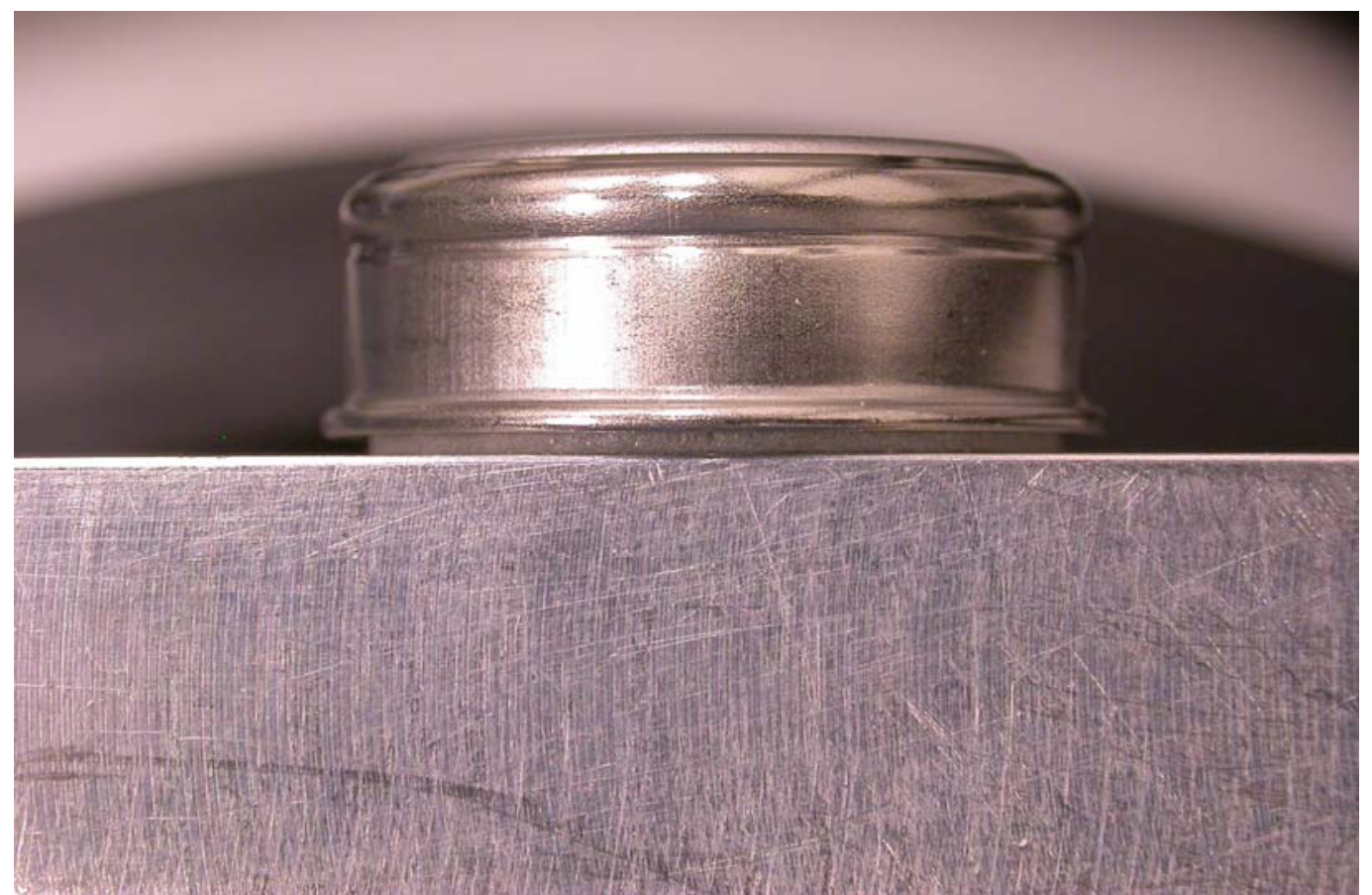

Figure 2.4 - DS1922L attached to the mounting plate with an adhesive pad.

The DS1922Ls were configured using ThermoTrack software from Proges-Plus. Parameters of the mission were a start delay of 5 minutes, $0.5^{\circ} \mathrm{C}$ resolution, and a 3second sampling rate. The 3-second sampling rate allows the DS1922L to acquire 8129, 8-bit readings for 6 Hours 46 minutes and 27 Seconds. A 5-hour test requires a minimum of 6000 samples, which is easily accommodated by the DS1922L. A status check of the DS1922Ls was performed $\sim 4$ minutes after the scheduled start time to verify they were acquiring data.

The VibeLab software was set to the test position with a programmed 5-hour run time. The system performed a pretest at $12 \mathrm{~dB}$ below the desired amplitude. When it was determined that the desired spectrum was being achieved, the amplitude was raised to the test level and maintained for the programmed time. The system and test parts were monitored for the first 20-minutes and then checked periodically at 30-minute intervals. The last 10-minutes if the test were monitored with the test ending after 5-hours.

\section{Test Results}

The reference/control accelerometer is monitored continuously during the testing and provides feedback for the shaker control. Vibration amplitude and the calculated PSD are only saved periodically for tests of this type. For tests with duration of more than a couple of hours, this was done at the beginning and at the end of the test period. The PSDs are shown in Figures 3.1 and 3.2. 
Vertical Excitation at Beginning of Test

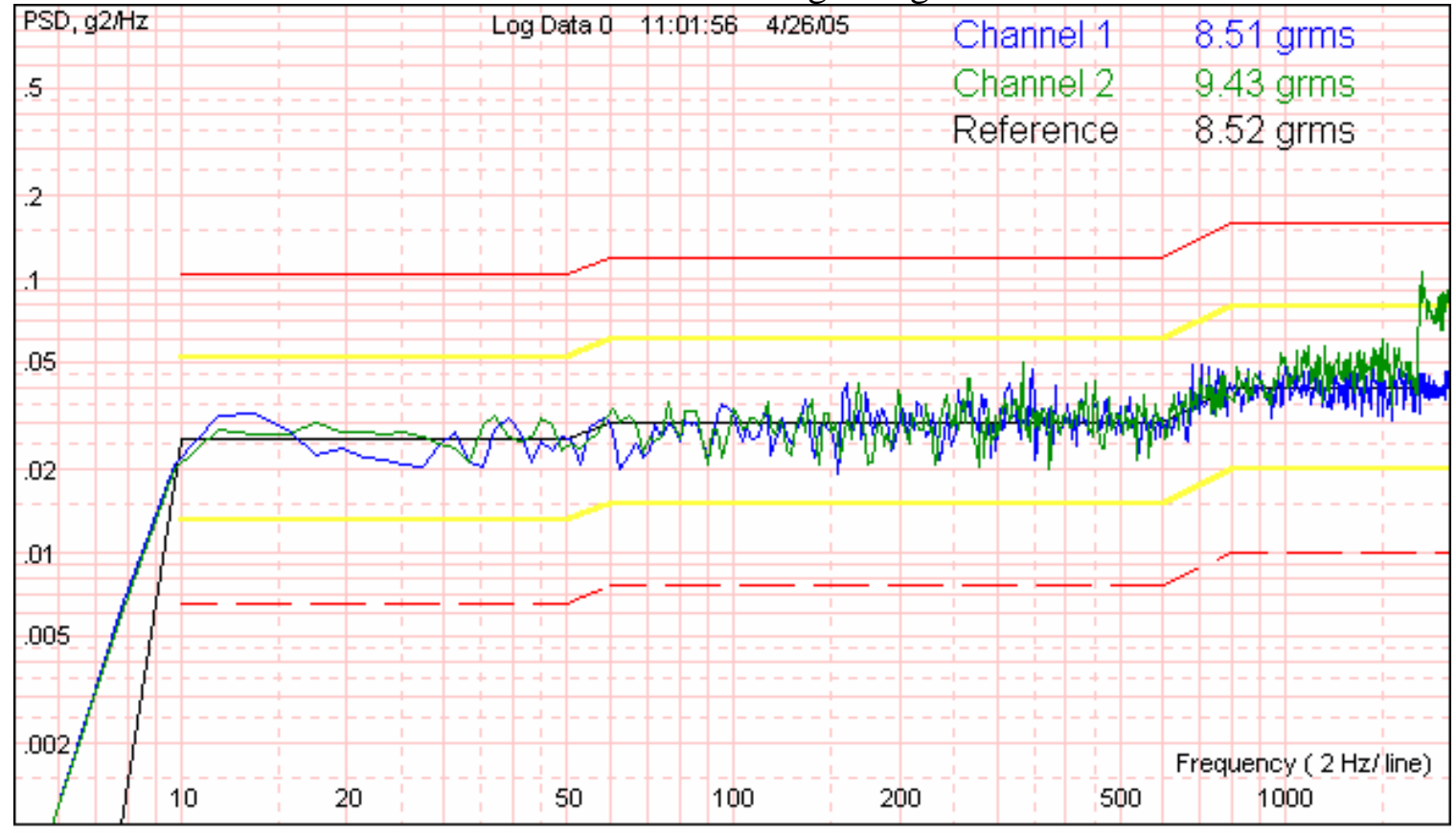

Figure 3.1 - Power Spectral Density plot taken at the beginning of test.

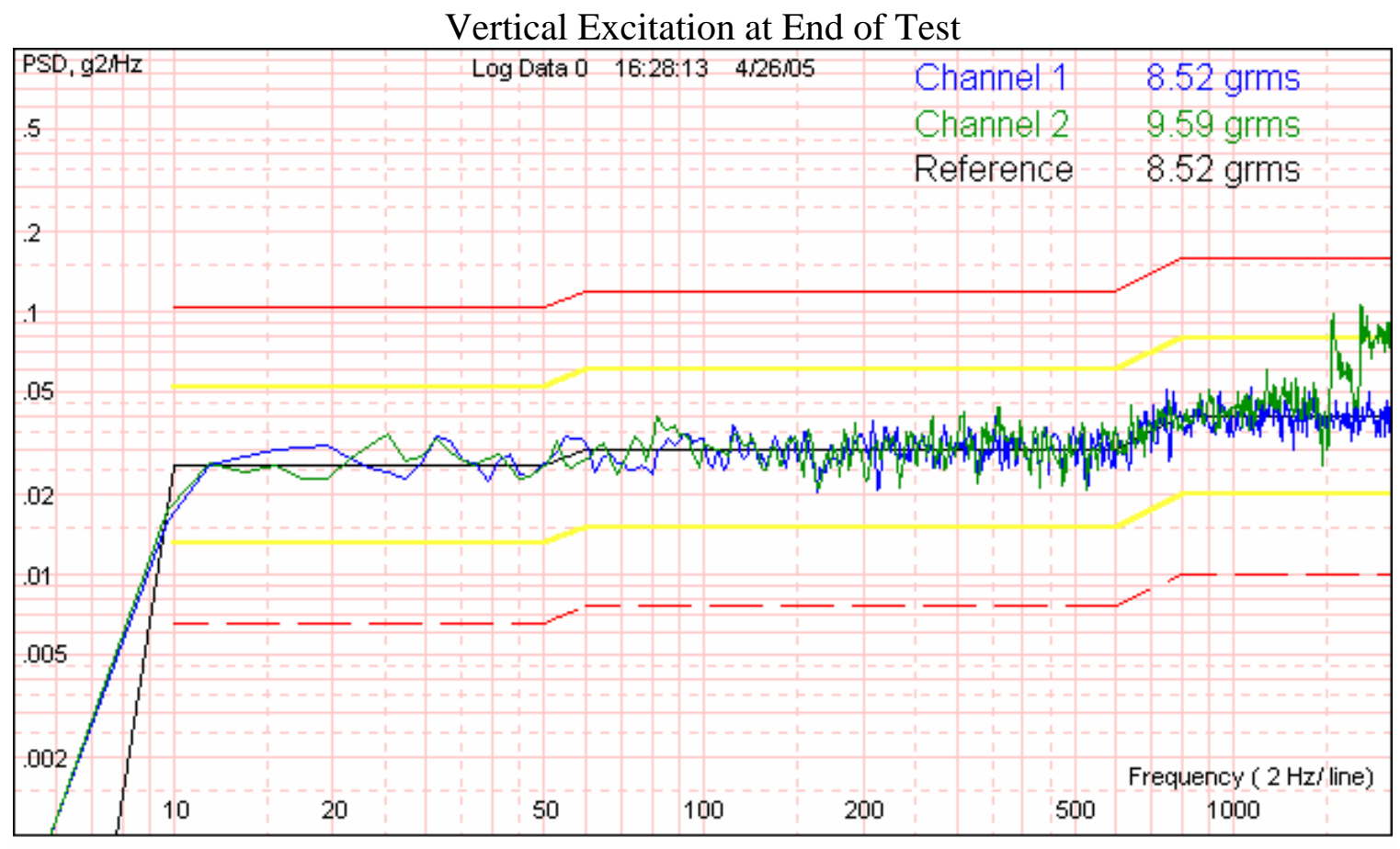

Figure 3.2 - Power Spectral Density plot taken at the end of test. 
At the end of the test period, a status check of the DS1922Ls was performed to verify functionality. Data acquisition was then stopped. The data was then downloaded to a laptop, archived and exported to an Excel format file. Figures 3.3 and 3.4 show the data plots from the data downloads. The plots show that data was continuously captured during the length of the test. Ambient room temperature during the test period was maintained at $72^{\circ} \mathrm{F}\left(22.2^{\circ} \mathrm{C}\right) \pm 1^{\circ} \mathrm{F}$.

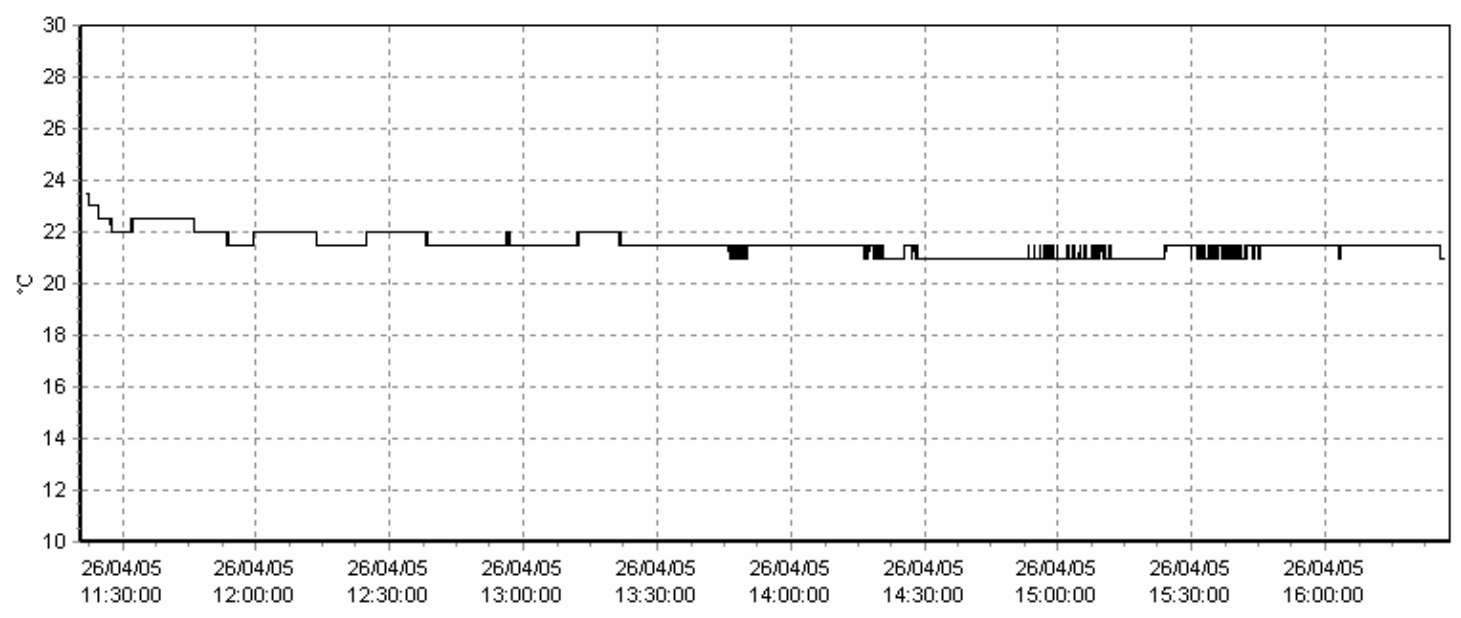

Figure 3.2 - Temperature Graph for Horizontally Mounted DS1922L, S/N $3800000001 F 63541$

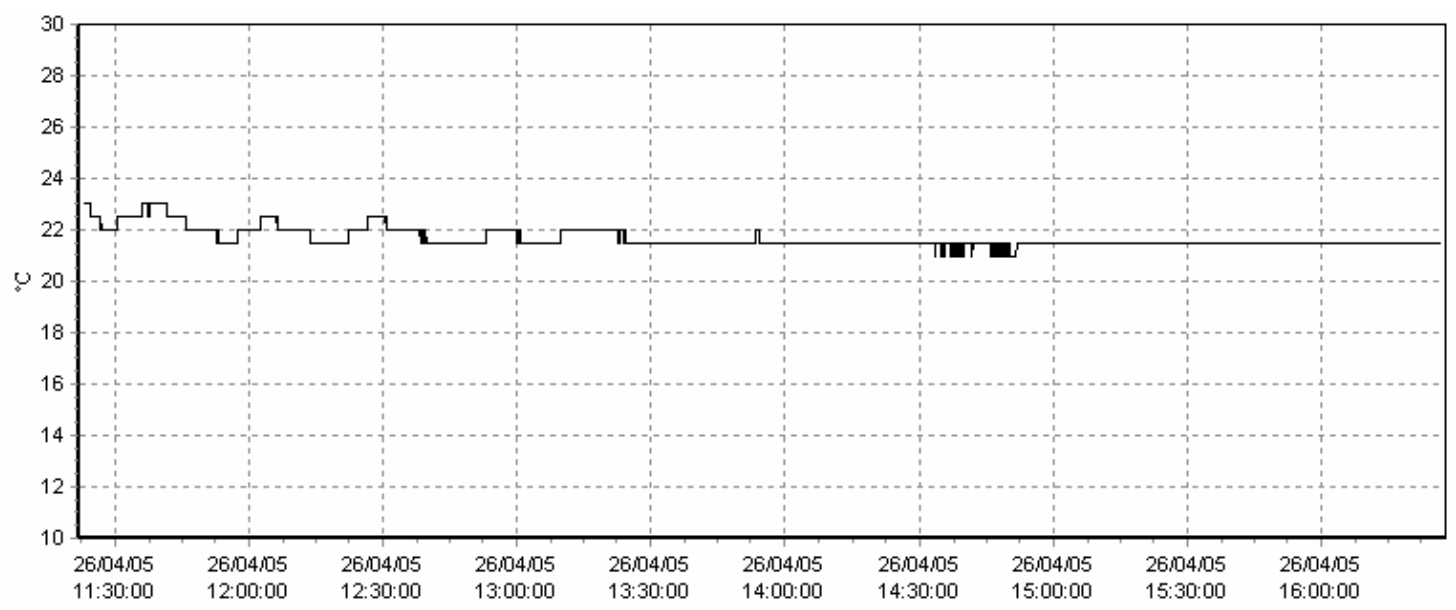

Figure 3.3 - Temperature Graph for Vertically Mounted DS1922L, S/N 8F0000000200F41 